\title{
«ES SIGNO DE ISLAS»: AGUSTÍN ESPINOSA Y EL ROMANCERO CANARIO*
}

\author{
Sabina Reyes de las Casas \\ Universidad de Sevilla
}

\section{RESUMEN}

Agustín Espinosa es uno de los autores más importantes de las letras canarias. Escritor polifacético, es poco conocida su labor como recopilador de romances insulares. En este trabajo veremos cuál era el estado de la investigación del romancero canario a comienzos del siglo xx y valoraremos la aportación pionera del autor de Crimen a este campo. Para ello, revisaremos lo que otros investigadores como Maximiano Trapero o Diego Catalán han escrito sobre el tema y propondremos una nueva lectura del trabajo romancístico de Espinosa que parte de su contexto, es decir, una lectura que deriva de un momento en el que la literatura canaria se preocupaba por fundamentar su existencia uniendo tradición, insularidad y vanguardia.

Palabras clave: Agustín Espinosa, romancero, vanguardias insulares.

"ES SIGNO DE ISLAS":

AGUSTÍN ESPINOSA AND THE CANARIAN ROMANCERO

\section{Abstract}

Agustín Espinosa is one of the most important authors of the Canary Islands. A multifaceted writer, his work as a compiler of island "romances" is little known. In this work we will see what was the status of the Canarian "romances" research at the beginning of the 20th century and we will value the pioneering contribution of the author of Crimen to this field. To do this, we will review what other researchers such as Maximiano Trapero or Diego Catalán have written on the subject and propose a new reading of Espinosa's research that starts from its context, that is, a reading that derives from a time when literature of the Canary Islands was concerned with establishing its existence by uniting tradition, insularity and the avant-garde.

KEYwords: Agustín Espinosa, romancero, avant-garde.

DOI: https://doi.org/10.25145/j.refiull.2021.42.05

Revista de Filología, 42; enero 2021, pp. 61-78; ISSN: e-2530-8548 


\section{INTRODUCCIÓN}

En la «Antología de la literatura surrealista en Tenerife» que forma parte del libro Facción española surrealista de Tenerife, el crítico Domingo Pérez Minik incluye a Agustín Espinosa como el primer nombre de su selección, acompañado de otras figuras importantes como Pedro García Cabrera, Eduardo Westerdahl, Emeterio Gutiérrez Albelo, Domingo López Torres, Juan Ismael González y José María de la Rosa ${ }^{1}$. Probablemente no es necesario este argumento de autoridad para sostener la afirmación de que Agustín Espinosa es uno de los autores más destacados de las letras canarias y del conjunto de las letras hispánicas, entre otros motivos por haber sido el autor de la novela surrealista Crimen (1934).

Sin embargo, Agustín Espinosa fue mucho más que un escritor surrealista. Fue un autor polifacético interesado no solo por la creación literaria, sino también por la investigación de diversas cuestiones entre las cuales no podía faltar una profunda preocupación por el estudio de la literatura canaria, tanto escrita como oral. El propio Pérez Minik se refiere a Espinosa en los siguientes términos en un artículo publicado en el periódico El Día el 30 de noviembre de $1980^{2}$ : «Todo le preocupaba, estaba en todo, todo le apasionaba. Lírico, narrador, ensayista, escribió también teatro, y la crítica literaria, nada le era indiferente» (Gaviño de Franchy 2009: 90).

Dentro de este amplio número de temas por los que nuestro autor se preocupó a lo largo de su vida, nos interesa aquí profundizar en su labor como compilador y estudioso del romancero. En este sentido, podemos afirmar que Espinosa fue «el primer investigador del romancero canario» ${ }^{3}$ o, en palabras de José Miguel Pérez Corrales,

Espinosa se anticipa a todos con la pesquisa de romances insulares emprendida en 1925 y que suponía el primer intento realizado en Canarias por entroncar con una tradición auténtica y viva, que él ve continuarse en el siglo barroco por Viana y Cairasco y en el siglo Xviı por la fecunda Ilustración insular (Pérez Corrales 1982-1984: 103).

Por su parte, la catedrática de Lengua y Literatura Margarita Rodríguez Espinosa, sobrina del escritor nacido en el Puerto de la Cruz, en su artículo "Cosas de tócame Roque», se refiere a la manera en la que percibían la figura de Espinosa desde su entorno más cercano, indicando lo que decían y destacaban de él aquellos

* En los distintos trabajos citados en este artículo, regularizamos la ortografía conforme a la norma española vigente desde 2010. Asimismo, omitimos las notas al pie presentes en los trabajos de Maximiano Trapero y Diego Catalán para agilizar la lectura del texto.

${ }^{1}$ Los mencionamos según el orden de aparición en la «Antología» de Pérez Minik.

2 El título del artículo es "Agustín Espinosa, aquí y ahora» y podemos leerlo íntegramente en Gaviño de Franchy 2009: 89-92.

3 Así lo califica el profesor Maximiano Trapero (1987-1988). 
que le conocieron, e incluye precisamente en esta descripción su labor como recopilador de romances:

Agustín era solo un personaje como de cuento que despertaba nuestra curiosidad y del que se hablaba con respeto y admiración. Había sido el catedrático más joven de Espańa. [...] Era quien había enseñado a recitar a una de las primas un poema de Juan Ramón Jiménez en una velada literaria [«Los niños tenían miedo, - yo no sé lo que sońaban»], o quien había recuperado un romance que a mí me acababa de enseñar en la escuela un profesor peninsular en una versión algo diferente (Rodríguez Espinosa 2009: 71-72).

E incluso Antonio Becerra Bolaños, docente e investigador de la Universidad de Las Palmas de Gran Canaria, al realizar una aproximación a la vanguardia en las Islas, apunta que

Espinosa, aparte de creador, es un estudioso de la literatura que se ha mostrado muy interesado por ciertos aspectos de la literatura canaria. A la elaboración de su tesis doctoral sobre la figura de Clavijo y Fajardo hay que unirle su interés por los romances. Clavijo y Fajardo le interesa más como figura novelesca que como escritor ${ }^{4}$, si bien no sería descabellado pensar que en él tuvo cierta influencia la obra del Pensador; de los romances, sobre todo, le fascina la forma en que éstos son re-escritos en las Islas (Becerra Bolaños 2000: 102).

Por tanto, podemos comprobar que existe unanimidad a la hora de reconocer a Espinosa el haber sido pionero en el estudio de nuestros romances insulares 5 . Como consecuencia, partimos de la idea de que su nombre debería aparecer en cualquier estudio sobre el romancero canario. Sin embargo, antes de adentrarnos en la figura de Agustín Espinosa para tratar de exponer cuál fue realmente su aportación a la investigación en la materia, es importante saber cuál era su nivel de desarrollo en las primeras décadas del siglo $\mathrm{xx}$.

${ }^{4}$ Esta idea está de manera explícita en su obra Lancelot, $28^{\circ}-7^{\circ}$ : «En Clavijo más que en la obra interesa la vida» (Espinosa 1988: 53).

${ }^{5}$ Espinosa es consciente de que es un pionero en el estudio del romancero, pues afirma que "fue como un auricular trotador por los caminos vírgenes de la poesía popular de las islas» (Espinosa 1980: 127), es decir, por caminos hasta entonces inexplorados. A pesar de ello, Maximiano Trapero recoge en su trabajo algunos datos muy interesantes sobre los orígenes del estudio de romances en las Islas, pues nos indica que «antes que Agustín Espinosa se habían interesado indirectamente por la recolección de romances populares Juan Bethencourt Alfonso, José Batllori y Lorenzo, José M. de Sotomayor y María Sánchez de Arbós», quienes enviaron romances desde diferentes partes del Archipiélago (Trapero 1987-1988: 432). Todo apunta a que la mayoría de los datos que aporta Trapero los toma directamente de La flor de la marañuela. Romancero general de las Islas Canarias (1969), editado por Diego Catalán. 


\section{EL ESTUDIO DEL ROMANCERO CANARIO}

A comienzos del siglo xx, el gran investigador Menéndez Pidal deseaba conseguir muestras del romancero canario para completar su romancero hispánico, así que decidió realizar un llamado a los intelectuales isleńos de la época mediante una publicación en la prensa de Tenerife, motivo por el cual envió un artículo al director del Diario de Tenerife, Patricio Estévanez y Murphy (Catalán 1969a: 10). El artículo, que llevaba por título «El romancero español y las Canarias», se publicó en el periódico anteriormente citado el 24 de enero de 1904. ¿Qué pretendía lograr Menéndez Pidal con aquella publicación? En gran medida, su objetivo final era tratar de paliar las carencias que de romances canarios había en las colecciones peninsulares, pues existía una gran desigualdad entre territorios en relación con la recolección de variantes. En este sentido, Menéndez Pidal consideró (con gran acierto, hemos de apuntar) que «esta desigualdad no depende de la riqueza de cada región, sino de si en ella hubo o no aficionados y eruditos colectores» (Menéndez Pidal 1904: 15). Por ello, busca convencer a las figuras más ilustradas de las Islas para que emprendan la difícil tarea de recolectar romances y les da algunos consejos que parten de su propia labor como recolector:

El romance vive en general escondido en el campo y hay que buscarlo con trabajo. Pero la tarea sobre ser relativamente sencilla, tiene cierto atractivo, y sobre todo un alto interés científico y artístico [...] La copia, claro es, debe hacerse con fidelidad absoluta, mecánica; la menor corrección que el colector deslice, aunque parezca muy evidente, puede traer una perturbación al comparar aquella versión con otras. [...] El colector de una sola debe abstenerse de toda enmienda que sería personal y anticientífica. Tampoco debe pulir el lenguaje, sino conservar palabras raras [...]. Será muy conveniente que la primera y la tercera recitación de cada romance sea cantada, si es posible lograr esto del recitador. El canto regulariza la medida del verso, y ayuda mucho al recuerdo. [...] Hecha la transcripción, debe apuntarse al pie el lugar donde el recitador ha aprendido el romance, y cualquier otra circunstancia de en qué ocasiones, por qué clase de personas, y cómo se canta y se acompańa (Menéndez Pidal 1904: 16-17).

Además de publicar este llamamiento, Menéndez Pidal también escribe personalmente a algunos de esos intelectuales destacados de las Islas para intentar convencerlos de que colaboren en su empresa (Catalán 1969a: 10). Según los datos que Diego Catalán encuentra en los archivos de su abuelo, la carta fue enviada a varias figuras importantes de la época radicadas en Tenerife, Gran Canaria, Lanzarote, La Palma y Fuerteventura (1969a: 10) ${ }^{6}$.

${ }^{6}$ En concreto, sabemos que Menéndez Pidal envió aquella misiva a las siguientes personas: «De Tenerife: A Manuel de Ossuna y Van-den-Heede, a Ramón de Ascanio, a Adolfo Cabrera Pinto, a Leandro Serra y Fernández de Moratín y a José de Moure, en la Laguna; a Maximiano Aguilar, en el Puerto de la Cruz. De Gran Canaria: A Amaranto Martínez de Escobar, a José Batllori y a Luis Millares y Cubas, en Las Palmas. De Lanzarote: a Antonio María Manrique, en Arrecife. De La 
Sin embargo, los resultados no fueron precisamente positivos y Menéndez Pidal no vio aumentada su colección de romances de la forma en la que él esperaba y deseaba:

En conjunto, muy escasa cosecha para cuanto se había vaticinado. Pero hay que tener en cuenta que se estaba en aquellos ańos primeros del siglo en los albores de la gran etapa recolectora del romancero tradicional moderno y que, por tanto, los conocimientos y predisposiciones que pudieran tener los «intelectuales de provincia» hacia un fenómeno tan específico como el romancero de tipo oral justificaban, por una parte, la apatía hacia una gran labor recolectora -siempre tan fatigosa- y, por otra, la falta de una correcta valoración histórica, literaria y folklórica de los textos recogidos. Sencillamente no entendieron el alcance de la empresa a la que con tanta insistencia los incitó Menéndez Pidal (Trapero 1987-1988: 433).

Como consecuencia, y a pesar de haberlo intentado con verdadero ahínco, el investigador «dejó de procurar activamente versiones canarias para su romancero hispánico, desalentado por los escasos frutos de su sostenida correspondencia con los medios isleños» (Catalán 1969a: 12).

Tras esta desastrosa situación inicial, la recopilación de variantes y el estudio del romancero canario iría mejorando a medida que avanzaba el siglo. Así, podemos decir que realmente «el descubrimiento de la tradición canaria es obra de los años 20, ya bien avanzados. Sólo entonces comenzó a salir, lentamente, del olvido el peculiar tesoro romancístico isleño" (Catalán 1969a: 19). Pues bien, es precisamente en el contexto de este descubrimiento de la tradición romancística canaria donde tenemos que situar la figura de Agustín Espinosa, quien envió a Menéndez Pidal en 1927 copia de los romances que ya había publicado en la revista $\mathrm{La}_{\text {Rosa }}$ de los Vientos ${ }^{7}$ y otros más que había recolectado previamente. Según señala Diego Catalán, «en la portada de la copia a máquina consta "Romancero Canario. B) Isla de Tenerife" y escrito de puño y letra del propio Menéndez Pidal: "Sr. Agustín Espinosa, 1927. Enviará de Gran Canaria, Lanzarote ${ }^{8}$ y el Hierro (unos 80)”» («Nota al pie 51», 1969a: 21).

Palma: a Elías Santos Abreu, en Santa Cruz. Más tarde, el 4 de junio, se dirigió también a Ramón F. Castañeyra, Puerto de Cabras, Fuerteventura» («Nota al pie 22», Catalán 1969a: 10).

${ }^{7}$ Esta revista tendrá un papel fundamental en el desarrollo de las vanguardias insulares. Para José Miguel Pérez Corrales, «la aparición de La Rosa de los Vientos, a la sombra cordial de La Gaceta Literaria [...] es el hito más importante de estos años -hito fundacional- en la literatura insular. Fruto del esfuerzo conjunto de Espinosa, Juan Manuel Trujillo y Ernesto Pestana. Espinosa colabora con los siguientes textos: "Azores mudados", "Romances tradicionales de Canarias" y dos reseńas [...]. El más importante de los cuatro textos, desde el punto de vista insular, es claramente la selección de romances que él ha ido recogiendo desde 1925 o 1926, y cuya trascendencia será puntualmente reconocida [...] por sus compañeros de generación» (1986a: 303).

${ }^{8}$ En una nota al pie de su artículo de 1987-1988, Trapero plantea que probablemente Espinosa también recogiera romances en la isla de Lanzarote: «Parece que Agustín Espinosa realizó también algunas encuestas en la isla de Lanzarote, en la época que ejerció allí como Catedrático de Instituto. Alfonso Armas, buen conocedor de la vida y de los archivos de Espinosa, nos comunica que a Sebastián Sosa, al realizar estas encuestas romancísticas por Lanzarote en los ańos 60, le comentaron 
Pero ¿qué pasó finalmente con el nuevo envío de romances procedentes de otras islas que Espinosa parece haber prometido a Menéndez Pidal? ¿Por qué nuestro autor se interesa por el romancero canario? Y, lo que es más importante, ¿`cuál fue realmente su aportación al estudio de la materia?

\section{TRADICIÓN, VANGUARDIA E INSULARIDAD: AGUSTÍN ESPINOSA Y EL ESTUDIO DEL ROMANCERO CANARIO}

Es difícil saber si Espinosa tuvo noticia de la publicación del artículo de Menéndez Pidal que hemos comentado o de alguna de las cartas que también envió (aunque sería lógico pensar que sí que la tuvo porque esto explicaría el envío de romances del investigador canario al gallego), pero lo que está claro es que, con independencia del motivo que lo animó a ello, el autor de Crimen decidió indagar en nuestra tradición oral. En este sentido, citar a Espinosa como estudioso del romancero canario parece haberse convertido en una mención obligada cuando hablamos de su figura, pero lo más habitual es quedarse en el mero apunte biográfico y anecdótico, pues normalmente no se estudia ni se profundiza en el tema, a excepción, claro está, del trabajo de Maximiano Trapero «Agustín Espinosa, primer investigador del romancero canario", publicado en esta revista misma hace ya más de treinta años.

Por tanto, si de verdad queremos contribuir de alguna forma a conocer mejor estas cuestiones, debemos destacar desde un principio que la labor de Espinosa fue la del buscador, recopilador y estudioso de lo que él mismo denominó «flor primera de romances de las islas Canarias»:

algunos informantes viejos que ya otro profesor de literatura les había preguntando [sic] antes por romances. Ese otro profesor anterior no pudo ser otro que Espinosa, pero de lo recogido allí nunca se ha tenido noticia» ("Nota al pie 18», Trapero 1987-1988: 452). Por otro lado, en su obra Lancelot, $28^{\circ}-7^{\circ}$, dentro del capítulo que lleva por título «Teguise y Clavijo y Fajardo» (Espinosa 1988: 49-56) y que está dedicado "A Azorín», nuestro autor incorpora un romance de la tradición insular: «Teguise es un pueblecito alegre, rumoroso, que hace girar su rueda de colores frente a la blanca arquitectura general de la isla [...]. Sobre la montaña, el castillo de Santa Bárbara pone su nota tradicional. De una tradición de incursiones africanas que el romancero de las Islas ha cantado con sentimiento propio. Dando categoría atlántica peculiar a un tipo de romance exactamente canario».

\footnotetext{
Mañanita de San Juan, como costumbre que fuera, las damas y los galanes a bañarse a las Arenas.

Laurencia se fue a bañar sus carnes blancas y bellas. Vino un barquito de moros y a Laurencia se la llevan.
}

(Espinosa 1988: 51-52). 
En esta flor primera de romances de las islas Canarias, he puesto mi honestidad de folclorista puro. Mi labor ha sido la labor del botánico. Botánico de la poesía popular, he recogido por los campos de Tenerife la flora poética que vuelco ahora en un libro. Botánico de la poesía popular, he clasificado, en ese libro, la flora encontrada (Espinosa 1980: 127).

Estas palabras que acabamos de citar se encuentran recogidas en el prólogo "Al lector» de la que probablemente sea la publicación más significativa que Espinosa realizó en torno a la literatura oral. Nos referimos al artículo «Romancero de los pueblos del sur de Tenerife», publicado en el periódico La Prensa el 24 de enero de $1932^{9}$. Sin embargo, los viajes durante los cuales Espinosa llevó a cabo la recolección de los romances que comenta habían tenido lugar años antes ${ }^{10}$ :

De 1926 datan mis primeros peregrinajes en la isla de Tenerife. Recorrí entonces, en actitud, y casi aptitud, de tal, Icod el Alto, La Guancha, Icod de los Vinos, Valle de Santiago, Guía de Isora y Adeje. El resultado fue encontrarme de improviso con un ventón de varios romances, cuya existencia no había sospechado siquiera, y que me animaron para posteriores rebuscas. De esta primera recolección son los que le di a don Ramón Menéndez Pidal para su magno Romancero español, tan escaso, hasta mi aportación, de variantes, verdaderamente populares, canarias (Espinosa 1980: 128).

No obstante, el autor de Crimen ya había publicado antes de 1932 algunos romances en La Rosa de los Vientos (abril, mayo y junio de 1927) ${ }^{11}$, pero en aquellas publicaciones prácticamente no se ocupaba de su análisis y los romances se presentaban de forma dispersa, frente a la presentación conjunta de varios de ellos y al análisis temático relativamente más amplio que presenta aquí, elementos que constituyen probablemente lo más novedoso de este trabajo de 1932.

Algunos críticos han considerado reseñable el hecho de que Espinosa publicase estos romances en las revistas de vanguardia de la época, como La Rosa de los Vientos (Tenerife) o Azor (Barcelona). Por ejemplo, a Trapero le llama «poderosí-

9 Citamos por Espinosa, Agustín (1980). Agustín Espinosa: textos (1927-1936) (ed. Alfonso Armas Ayala y Miguel Pérez Corrales), Santa Cruz de Tenerife: Aula de Cultura, 127-133.

${ }_{10}$ Conviene apuntar que la fecha de recolección de estos primeros romances puede oscilar entre 1925 y 1926, según la publicación que consultemos. En el artículo de La Prensa que acabamos de citar (1932), Espinosa menciona la fecha de 1926, mientras que en 1927 había señalado que sus pesquisas comenzaron dos años antes, es decir, en 1925: «Espinosa afirma en "Romances tradicionales de Canarias" [1927] que los romances que poseía los había encontrado "los dos pasados ańos". Sin embargo, en el "Romancero de los pueblos del Sur de Tenerife" [1932] dirá que sus "primeros peregrinajes folclóricos” datan del verano de 1926» («Nota al pie 13», Pérez Corrales, 1986a: 13).

${ }^{11}$ En La Rosa de los Vientos, indica Espinosa lo siguiente: «Publicamos tres romances recogidos en el sur de la isla -Valle de Santiago, Guía de Isora, Adeje- durante el verano de 1926» (Espinosa 1980: 128). Así, en total, en los cuatro primeros números de La Rosa de los Vientos, publicó ocho romances: La devota de San Francisco (á.a), La bastarda y el segador (á.a), Santa Iría (á.a), Sildana (í.a), Los cautivos Melchor y Laurencia (é.a), La serrana de la Vera (é.a), Marinero al agua (á.a) y Riña en el campo (á.o). 
simamente la atención que una revista que fue desde el principio portavoz de las ideas literarias y estéticas más avanzadas de la época, que nació precisamente con esas características, acogiera en sus páginas la literatura más vieja que representaba el romancero tradicional» (1987-1988: 435). Sin embargo, esta percepción debería ser matizada, pues entendemos que en el momento en el que Espinosa escribe era fundamental recurrir a la tradición para fundamentar la existencia de una literatura canaria:

Espinosa escribe en «Lancelot y Lanzarote» que «una tierra sin tradición fuerte, sin atmósfera poética, sufre la amenaza de un difumino total». Esta cita compendia su doble labor en el terreno insular: mirada hacia atrás en busca de una tradición viva, mirada hacia un presente que alumbren las luces solas de la poesía y del mito. Este programa poético lo va a llevar a efecto tanto en lo teórico presente y atribuyendo él mismo de modo esencial, en lo creativo, a esa cultura (Pérez Corrales 1986 I: 361).

Por tanto, incluso aunque defendiésemos que Espinosa se mueve entre dos polos opuestos y trabaja con dos visiones antagónicas del arte como son la tradición y la vanguardia (cosa que ciertamente hace), no tenemos por qué pensar que necesariamente ese antagonismo implica exclusión. Un mismo autor puede ser portavoz de ambas perspectivas, pues el hecho de adherirse a una no conlleva la omisión de la otra. En este sentido, destacamos la opinión del crítico Eugenio Padorno, quien señala que

en la evolución de la estética de Espinosa, al tiempo que se registra un desplazamiento hacia los reclamos europeos de las avanzadas artísticas, desde el creacionismo hacia el cubismo y el surrealismo, no deja de darse un desplazamiento en sentido opuesto hacia reclamos u horizontes originarios, actitud que explica y justifica en Espinosa al recolector de romances y al admirador de Cairasco y Viana. Lo canario no es enemigo del espíritu de la vanguardia y, lejos de incitar a la ruptura de la tradición anterior, invita a fortalecerla (Padorno 2000: 20) ${ }^{12}$.

Después de haber publicado el artículo en La Prensa al que ya nos hemos referido, «un año más tarde, en 1933, no sabemos con qué motivo, publica en la revista Azor de Barcelona (15 de enero de 1933) una colección de "romances de Tenerife"13. Pero no aporta nada nuevo aquí porque se limita a reproducirnos los 5 primeros títulos de La Rosa de los Vientos» (Trapero 1987-1988: 436). A estas refe-

12 En relación con este aspecto, convendría tener también en cuenta la importancia del neopopularismo en las vanguardias españolas del siglo xx. Por ejemplo, Maximiano Trapero menciona la influencia que este tema puede haber ejercido sobre Espinosa cuando plantea que probablemente el encuentro entre nuestro autor y el romancero fuera simplemente casual o quizás fruto de esta "moda" presente entre los poetas e intelectuales españoles de la época (1987-88: 439).

${ }_{13}$ Reproducimos aquí la «Nota al pie 26» del artículo de Trapero: «Esta noticia la recogemos directamente de FM, p. 23 y de M. Pérez Corrales, Agustín Espinosa, entre el mito y el sueño, I, Las Palmas, Cabildo Insular de Gran Canaria, p. 362» (1987-1988: 452). 
rencias, habría que añadir el último trabajo de Espinosa relacionado con el estudio del romancero que de manera póstuma vio la luz en Santa Cruz de Tenerife en 1940. Se trataba de un pequeño libro que formaba parte de "la denominada "Biblioteca Canaria" con el título Romancero Canario ${ }^{14}$ " y que perseguía o pretendía "ser una antología de los romances recogidos hasta la fecha en Canarias, agrupados según las aportaciones de cada recolector» (Trapero 1987-1988: 436).

En su artículo de 1932, trabajo que aquí hemos considerado el más significativo, Espinosa dice haber encontrado «cerca de un centenar de romances, algunos de gran interés regional y nacional al mismo tiempo, ya por razones de no existir de ellos variantes peninsulares, ya por ser de una belleza popular superior a la de sus correspondientes continentales» (1980: 128). Sin embargo, lo cierto es que, a pesar de que incorpora ejemplos de diferentes romances, ni en este trabajo de 1932 ni en las publicaciones previas de La Rosa de los Vientos, ni mucho menos en el envío realizado a Menéndez Pidal, encontramos ese centenar que el investigador había anunciado.

Llegados a este punto, conviene preguntarse qué dice Diego Catalán en La flor de la marañuela sobre los romances que sabemos con certeza que Espinosa envió a Menéndez Pidal y, en general, sobre el número total de los que recolectó. En este sentido, la hipótesis que plantea el investigador madrileño en 1969 se basa en la idea de que

la insistente utilización por parte de Espinosa, en 1927, 1932 y 1933, de un número tan limitado de textos, lleva a pensar que la «Flor primera de romances de las Islas Canarias» no debía ser tan abundante como su formador quiso dar a entender. ${ }^{15}$ Sin embargo, la pobreza del inventario puede ser debida, simplemente, al criterio selector: Espinosa se interesaba sólo por lo que de «canario» pudiera haber en el romancero tradicional de Canarias y subordinaba su valoración de los romances recogidos a la pretendida originalidad temática o, por lo menos, formal, que en ellos creía descubrir (Catalán 1969a: 23).

A pesar de esta valoración, si consultamos el «Índice de colectores» de la Flor de la marañuela (Catalán 1969b: 263-265), encontramos a Espinosa entre los nombres destacados, aunque Diego Catalán considera que no es uno de «los recolectores que han proporcionado por sí solos una "flor" completa" (1969 II: 263). En total, en este Indice se mencionan 19 romances recolectados por Espinosa. Sin embargo, a la hora de estudiar el romancero tradicional canario, de estos 19 romances deberíamos descartar tres que pertenecen realmente al conjunto de «romances de pliego de cordel cantados en Canarias» (Catalán 1969b: 238-249), según la teoría propuesta por Diego Catalán. Como consecuencia, los dieciséis romances tradi-

${ }^{14}$ Reproducimos la «Nota al pie 27» del artículo de Trapero «Romancero Canario (Antiguos romances tradicionales de las islas), Librería Hespérides, Santa Cruz de Tenerife (1940)»(1987-88: 452).

${ }^{15}$ Esta idea será también defendida tiempo después por el estudioso del romancero canario Maximiano Trapero, pues según su opinión «es posible que, efectivamente, el número de título fuese sólo [sic] de 19 y que el "casi centenar" lo fuese de versiones variantes de esos títulos” (1987-88: 434). 
cionales que nos quedan son los siguientes: «El conde Claros en hábito de fraile», "La mala hierba», "Alba niña», "Sildana», "Delgadina», "La serrana», "La bastarda y el segador», "La devota de San Francisco», "Las señas del marido», "Marinero al agua» (versión contaminada por «El idólatra»), «Santa Iría», «El indiano burlado», «Los cautivos Melchor y Laurencia», «Diego de León», «El mercader de Sevilla» y «Riña en el campo».

La mayoría de estos dieciséis romances fueron remitidos en 1927 a Menéndez Pidal (catorce de ellos, para ser exactos, a excepción de «El indiano burlado» $\mathrm{y}$ «Los cautivos Melchor y Laurencia»), pero todos no están incluidos en el artículo que Espinosa publica en La Prensa en 1932. En este trabajo se hace referencia solamente a los romances «La devota de San Francisco», «Marinero al agua», «El indiano burlado»y "Riña en el campo». Sin embargo, aunque la muestra puede parecer algo pequeña, consideramos que lo realmente interesante de su trabajo de 1932 es preguntarse qué metodología emplea Espinosa a la hora de presentar y analizar los romances. Pues bien, nuestro autor los agrupa a partir de su contenido, estableciendo así cuatro apartados dentro de su investigación: «Romances de cautivos», "Romances de indianos», «El lego de San Francisco» y «El sentimiento del mar».

Desde su perspectiva de análisis, Espinosa considera que los romances de cautivos son producto de «las incursiones moriscas a nuestras islas, periclitadas con Carlos III, y cuya antigüedad se remonta a los primeros guanches", elementos que «nos dan la pista de su regional origen» (1980: 129). Los de indianos, por su parte, tendrían que ver con el viajero que regresa de hacer las Américas, pero «los años [...] han borrado de las Islas la fisionomía del viajero. Es éste, generalmente, quien tiene que descubrirse, ante su misma madre, que lo reconoce alborozada, o, a veces, ante su propia esposa» (Espinosa 1980: 131). En cuanto al lego de San Francisco, considera que este romance tiene que ver con el protagonismo de las órdenes franciscanas en Canarias ${ }^{16}$. Por último, el sentimiento del mar es probablemente el tema que más le interesa y, además, consideramos que es el elemento más llamativo de su reflexión en torno al romancero canario.

En relación con el último asunto señalado, el autor de Crimen se interroga sobre ese «signo de Islas» que es el mar (Espinosa 1980: 132) y trata de dar una respuesta válida a sus preguntas:

¿Cómo siente el mar nuestro romancero? ¿Se crea en Canarias, por su influencia, un tipo propio -regional- de romance? ¿El mar da el tema, aparece alguna vez, como verdadero personaje? ¿ $\mathrm{O}$ siente sólo su influencia en el paisaje de nuestro romancero y en el cariño por las fábulas que sobre este escenario se asientan? (Espinosa 1980: 132).

16 Para Agustín Espinosa, «la primacía no sólo de antigüedad sino de extensión geográfica y número de establecimientos, que ha tenido en Canarias sobre las otras órdenes la franciscana, explican bien la formación de un romance cuyo protagonista es un monje de esta orden» (1980: 131). 
Es evidente que en este fragmento nos encontramos con el estudioso de la literatura, con el crítico, con el conocedor de la teoría literaria, facetas que le permiten plantearse estas cuestiones. Así, a partir de esta reflexión, nuestro autor pone en relación el tema del mar con la pervivencia de dos tipos de romances que ya había mencionado y comentado antes: los de cautivos y los de indianos. Desde su punto de vista, «el mar pone, en ambos casos, un camino azul entre Canarias y la India o la Morería. Sobre este azul camino va el indiano a la India y a la Morería el cautivo" (Espinosa 1980: 132) ${ }^{17}$. Sin embargo, a pesar de este planteamiento que pretende desentrañar lo que de canario hay en nuestro romancero, concluye su artículo afirmando que

la más interesante elaboración del mar en el romance canario no se produce así, ni se expresa en sus romances más propios. Sino embelleciendo y ampliando hasta lo no sospechado romances marinos peninsulares. Y-lo que es aún más maravillosoprestando nueva poesía a poemas populares del pueblo que más ha vivido del mar y que a él -al mar- le debe todo: Portugal (Espinosa 1980: 133).

Como estamos viendo, la forma que tiene Espinosa de agrupar y analizar los distintos romances remite a una clara conciencia del imaginario atlántico que no podemos obviar ni pasar por alto en este trabajo. Por tanto, consideramos que no es posible desligar su labor como recolector de romances de su propio sentimiento de insularidad, ni tampoco de la búsqueda y defensa de una «literatura canaria» que nuestro autor había emprendido tiempo atrás.

No obstante, la selección y valoración que Espinosa hace de los romances ha suscitado otras interpretaciones y, por supuesto, críticas, como las de Maximiano Trapero, el gran investigador del romancero canario, quien señala, no sin razón, que

una cierta obsesión por ver en los romances canarios particularidades y singularidades exclusivas, incluso especímenes autóctonos, desvirtúa la aportación de todas formas fundamental de Agustín Espinosa a la historia del romancero canario [...]. Una actitud así-tan elogiable desde un punto de vista local- produce importantes carencias desde el punto de vista científico, pues el romancero tradicional no es un fenómeno que pueda explicarse desde una perspectiva local, ni regional, ni incluso nacional. La tradición romancística sobrepasa el ámbito de lo español para elevarse al ámbito de lo hispánico, asentado en una geografía universal (Trapero 1987-88: 440).

Trapero critica a Espinosa por concentrarse en los romances de tema canario y omitir el estudio del romancero general hispánico, pero al realizar esta afirmación parece olvidar dos cosas: la primera, que Espinosa no niega que la tradición romancística sea un asunto supranacional, como hemos mencionado al leer su opinión

${ }_{17} \mathrm{Si}$ acabamos de decir que esas preguntas que se hace Espinosa sobre la importancia del mar en el romancero canario son propias de un conocedor de la teoría y la crítica literaria, conviene tener en cuenta que este «camino azul» es mucho más propio de su faceta como escritor, como literato. En cualquier caso, ambas ideas proceden del hombre de letras. 
sobre la importancia del mar en el romancero canario, tema que hace dialogar con los romances peninsulares y portugueses; la segunda, que el autor de Crimen no es el único que actúa de esta forma, tal y como recoge Diego Catalán en «El Romancero en Canarias. Notas históricas", texto que sirve a modo de prólogo al primer tomo de su Flor de la marañuela. Antes que Espinosa existieron algunos intelectuales que también se interesaron en lo que de canario pudiera haber en la literatura oral (no solo en el romancero), como es el caso de Benigno Carballo Wangüemert en relación con la isla de La Palma ${ }^{18}$ o del médico Juan Bethencourt Alfonso ${ }^{19}$, entre otros. Por tanto, si bien es cierto que el estudio del romancero sobrepasa con creces el ámbito de lo local o regional, descontextualizar la labor de Espinosa nos llevaría a realizar una crítica verdaderamente voraz que ensombrecería su labor y su aportación al estudio del romancero canario, por lo que sería conveniente tratar siempre de analizar su papel en el marco de la fijación y consolidación de las bases de la literatura canaria dentro de este período.

En cualquier caso, si algo hay que echarle en cara a Espinosa sobre este tema, una posible disculpa o justificación nos la proporciona él mismo en su conocida comunicación «Sobre el signo de Viera $»^{20}$ cuando afirma que

si alguna vez el corazón de Viera se rellena de júbilo, es contando el claro cuento de Dácil, o relatando el viaje de Hércules, o la muerte de Guillén Peraza, el príncipe que murió en pecado inmortal.

Ante la poesía popular de sus Islas, Viera olvida su prestigio erudito, su severidad de historiógrafo y hace poética historia, y, con el corazón entre sus manos, canta las excelencias de nuestro folklore (Espinosa 1980: 302).

Por tanto, tal vez haya sufrido Espinosa la misma suerte que Viera al encontrarse con la tradición del romancero en nuestras Islas. Quizás en su empeño por delimitar una literatura canaria con características propias no es capaz de desha-

${ }_{18}$ Nos referimos a algunas apreciaciones recogidas en la obra de B. Carballo Wangüemert Las Afortunadas. Viaje descriptivo a las Islas Canarias, editada en Madrid en 1862 (Catalán 1969b: 4-5). Para Catalán, es evidente que «Carballo sólo se interesa por los romances de asunto canario» («Nota al pie 7», 1969b: 5).

19 Diego Catalán nos ofrece también bastantes datos sobre la labor llevada a cabo por Bethencourt Alfonso: «En setiembre de 1903 Menéndez Pidal se dirigió al médico Juan Bethencourt Alfonso, cuya afición por el folklore isleño le constaba a través de Luis Maffiotte. Bethencourt había puesto en circulación por el archipiélago, en 1885, un Cuestionario folklórico, donde se preguntaba por "Romances populares no coleccionados"; pero su interés se centraba en la poesía narrativa de asunto canario, y por tanto el romancero tradicional quedaba prácticamente excluido de su "voluminoso fárrago de poesía popular"», según las palabras del propio Bethencourt (Catalán 1969b: 7).

${ }^{20}$ Esta conferencia que el escritor tinerfeño pronunció el 1 de enero de 1932 aparece recogida en el siguiente volumen por el que la citamos en este trabajo: Espinosa, Agustín (1980): «Sobre el signo de Viera", en Agustín Espinosa: textos (1927-1936) (ed. Alfonso Armas Ayala y Miguel Pérez Corrales), Santa Cruz de Tenerife: Aula de Cultura, 296-303. 
cerse del signo insular a la hora de llevar a cabo su investigación sobre la tradición romancística.

Si hablamos del «signo insular» bajo (o sobre) Agustín Espinosa, debemos tener en cuenta la comunicación que José Miguel Pérez Corrales pronunció en la Real Sociedad Económica de Amigos del País de Tenerife que llevaba por título «La conciencia de lo canario en Agustín Espinosa» (1984) y que posteriormente sería recogida en el Anuario del Instituto de Estudios Canarios. Aunque en aquella ocasión este gran conocedor de la figura de Espinosa y del surrealismo no se pronunció acerca de la labor del escritor tinerfeño como estudioso del romancero, sí que plantea algunas ideas que nos parece importante recuperar para comprender mejor la relación que mantuvo el autor de Crimen con el espacio insular y con la tradición literaria canaria:

El signo insular de Agustín Espinosa [1897-1939] constituye, junto a su aportación surrealista, lo más actual de este escritor. Espinosa nos dice en Lancelot, con palabras que nunca repetiremos lo suficiente, que «una tierra sin tradición fuerte, sin atmósfera poética, sufre la amenaza de un difumino total». Esta frase compendia su doble labor en el terreno insular: mirada hacia atrás en busca de una tradición viva, mirada hacia un presente que alumbren las luces solas de la poesía y el mito. Este programa poético lo va a llevar a efecto tanto en lo teórico como en lo práctico, indagando en la cultura insular del pasado y del presente y contribuyendo él mismo de modo esencial, en lo creativo, a esa cultura (Pérez Corrales 1982-1984: 102).

Nosotros entendemos que esa mirada al pasado «en busca de una tradición viva», como plantea Pérez Corrales, debe ser entendida de una forma bastante amplia y abierta. Corrales aplica su idea a la ampliamente conocida y citada conferencia «Sobre el signo de Viera» a la que ya hemos aludido aquí. En aquel trabajo, el autor tinerfeño «desvelaba el signo esencial del gran polígrafo canario y encomendaba a la cultura de las Islas dos altas misiones: la indagación lírica en lo propio y la zambullida perenne en lo universal» (Pérez Corrales 1982-1984: 103).

¿Cómo logra Espinosa ser también partícipe de esas dos grandes misiones que encomienda a la cultura canaria? Pues lo hace de muchas formas que entroncan, a su vez, con el valor universal de su obra a través del teatro, de la pintura o del cine. A estos aspectos señalados debería sumarse también la relación existente entre esta idea de la doble misión cultural de las Islas y la labor de Espinosa como recolector y estudioso del romancero, relación que constituye probablemente la idea más importante que hemos tratado de presentar en este trabajo. Como consecuencia, este planteamiento que estamos realizando solamente podría tener sentido si lo leemos en el marco de lo propuesto por Pérez Corrales, quien entiende que

Espinosa cree en un arte y en un alma insulares, en una "definición propia» y en una "personalidad canaria». Pero piensa que no es por la Historia, sino por la Geografía, como se llegará al «corazón» de lo insular. [...] Espinosa clavó lo insular en lo universal por medio de la reflexión poética sobre el paisaje y, a veces, sus gentes. Del paisaje destacó elementos esenciales -le interesa lo esencial y no lo anecdótico-, el mar, la luz -claridad atlántica inconfundible-, la tierra -la isla-, el cielo, el clima (Pérez Corrales 1982-1984: 105). 
En este sentido, hemos visto que normalmente son los elementos propios del espacio insular los que el autor destaca en sus aproximaciones al romancero canario. Así, a través de la esencia del paisaje canario y de sus gentes, lo insular pasa a formar parte de lo universal, como universal es también el romancero.

Por otro lado, todos podemos estar de acuerdo en la idea de que ser pionero no es tarea fácil y frecuentemente la inexperiencia propia del que comienza a abrir camino en una selva inhóspita puede acarrear numerosas críticas, como las que Maximiano Trapero le dedica a Espinosa a finales de los ochenta en el artículo al que ya hemos aludido aquí, cuando apunta que «los comentarios e ideas de Agustín Espinosa sobre el romancero tradicional participan de la provisionalidad que los albores de todo conocimiento conllevan» (1987-1988: 439). En este sentido, debemos decir que, pese a reconocer que Espinosa fue el primer investigador del romancero en nuestras Islas, Maximiano Trapero observa diferentes fallos en sus planteamientos que vendrían a sumarse a la crítica que realiza a su obsesión por localizar solamente romances dotados de un fuerte componente canario. En primer lugar, Trapero señala que "el "cuerpo" teórico de Agustín Espinosa sobre el romancero de Canarias es muy breve» (1987-1988: 438). Asimismo, considera que «se nota [...] el desconocimiento de la literatura [crítica, análisis y teoría literaria] sobre el romancero oral que ya por entonces empezaba a ser importante» (Trapero 1987-1988: 439).

Sin embargo, no queremos dar aquí una visión parcial de lo planteado por Trapero, pues no todo lo que dice de Espinosa es negativo. En este sentido, aunque la opinión de Trapero acerca de los orígenes de la recolección de romances en nuestras Islas coincide en lo fundamental con la de Diego Catalán, sí que deberíamos preguntarnos cuál es la principal diferencia entre los protorrecolectores de romances y nuestro Agustín Espinosa para comprender por qué fue tan importante su labor. Pues bien, en primer lugar conviene señalar que, al contrario que aquellos que antes que él habían estado interesados de alguna forma en la recopilación de romances que había promovido Menéndez Pidal,

Agustín Espinosa partía de unas condiciones profesionales que mejoraban notablemente las de sus predecesores en el momento de enfrentarse al fenómeno del romancero tradicional. Su doble condición de creador y de profesor de literatura le proporcionaban las herramientas idóneas para ser el investigador que necesitaba el romancero de Canarias (Trapero 1987-1988: 433).

Todo esto implica que «destacan, por lo ajustadas y ciertas que son, otras muchas observaciones e intuiciones sobre el romancero canario y sobre el romancero en general. Y es digno de destacar también el rigor "científico" con que se enfrenta al estudio de los textos orales recogidos» (Trapero 1987-1988: 439). ¿Por qué habla Trapero de ese rigor "científico»? Aquí encontramos uno de los aspectos más llamativos de la labor de Espinosa como recopilador del romancero, pues «los romances los transcribe siempre en versos octosílabos [...] teniendo siempre un exquisito cuidado por reproducir con toda fidelidad lo oído, intentando una casi transcripción fonética y señalando con precisión los diálogos de los personajes» (Trapero 1987-1988: 439-440). Este hecho entronca, una vez más, con la puesta en valor de lo canario dado que el autor de Crimen se preocupa también por trasladar al papel las carac- 
terísticas propias del habla canaria con las que se encontró durante su labor como recolector, aspecto digno de mención y valoración. En este sentido, Espinosa se interesa por la poesía propia del romancero tradicional, distinguiéndolo claramente del romancero nuevo de autor conocido y elaborado a imitación de la vertiente popular ${ }^{21}$.

Por último, nunca debemos olvidar que Agustín Espinosa solamente da los primeros pasos:

Espinosa inicia su prospección en el pasado isleño antes que nadie, con su tesis sobre el tan olvidado como relevante Clavijo y Fajardo, en 1924, y con su pesquisa de romances. Esta última labor [...] fue considerada por su generación -Juan Manuel Trujillo, Eduardo Westerdahl, Ernesto Pestana, Gutiérrez Albelo, Valbuena Pratcomo absolutamente capital (Pérez Corrales 1986 I: 361).

Después de él surgirán otros importantes investigadores del romancero canario, en mejores circunstancias, pues «el clima cultural necesario, para sacar de su vida latente al romancero de las Islas Canarias, sólo llegó a formarse con la introducción de la especialidad de Filología Española en la Facultad de Filosofía y Letras de la Universidad de La Laguna» (Catalán 1969a: 43). Nos referimos a nombres como los de Juan Régulo Pérez (versiones de Garafía y Mazo, en La Palma), Violeta A. Rodríguez (versiones de San Miguel y Fasnia, en Tenerife), Sebastián Sosa (Agaete y La Lechucilla, en Gran Canaria, además de otros lugares del Archipiélago), Isabel Ascanio (versiones de Agulo, en La Gomera), Francisco Tarajano (Agüimes, en Gran Canaria), María Jesús López de Vergara y Mercedes Morales (en Tenerife) (Catalán 1969a: 43-44), todos ellos figuras que merecen también nuestro respeto y reconocimiento por su labor como recolectores del romancero canario.

\section{CONCLUSIONES}

La literatura de transmisión oral es una de las piezas más importantes de nuestra tradición literaria, aunque muchas veces sea ignorada y, como consecuencia, olvidada dentro de la Historia de la literatura. Por tanto, entendemos que es nuestro deber reconocer la labor de aquellos que se han preocupado por mantener viva la literatura oral en diferentes ámbitos. En este sentido, son muchos los nombres que deberíamos mencionar dentro de nuestras Islas y, en general, en el mundo hispánico, pues sería necesario englobar tanto a quienes lo han hecho en el pasado como quienes continúan trabajando duramente a día de hoy para salvaguardar nuestras señas de identidad.

${ }^{21}$ En palabras de Maximiano Trapero, Espinosa «supo caracterizar desde el principio la esencia de la poesía verdaderamente popular y tradicional del romancero, en contraste con la poesía pseudopopular de los romances de autor individual que, a imitación de los tradicionales, abundan tanto en las literaturas locales de todas las regiones» (1987-1988: 440). 
Sin embargo, consideramos que de entre todos ellos no podemos olvidar nunca a los pioneros, pues ellos abrieron un camino que después muchos han seguido, probablemente con más medios y más éxito, pero siempre ha hecho falta que una persona diese ese primer paso, que marcase la senda. Por tanto, en Canarias, el pionero en el estudio del romancero fue Agustín Espinosa y, sin desmerecer el fantástico trabajo que otros han hecho después, como por ejemplo el estudio del romancero tradicional de La Palma (1948-151) llevado a cabo por José Pérez Vidal o los trabajos de Maximiano Trapero, el hecho de haber sido pionero en este campo es algo que nadie puede negarle a nuestro autor. En consecuencia, podemos decir que, a través de sus pesquisas, Espinosa emprende la «búsqueda de una tradición poética viva» (Pérez Corrales 1986a: 13), situando al romancero canario como un primer momento de la tradición literaria insular (Pérez Corrales 1986a: 363).

El romancero, esa «linfa que nutre, sin agotarse nunca, toda la literatura española», como lo definió Jean Canavaggio (1994: 46) en su conocidísima y ampliamente citada Historia de la literatura española, se convierte para Espinosa en una suerte de elemento que le permite, o al menos así lo entiende él, abarcar tanto «la indagación lírica en lo propio» como «la zambullida perenne en lo universal», palabras de Pérez Corrales que ya hemos señalado aquí. En esos romances que reúne, Espinosa cree ver las características propias de un espacio insular, pero esto no implica necesariamente negar que el romancero forme parte de una tradición hispánica que sobrepasa fronteras insulares, regionales y nacionales ${ }^{22}$. En este sentido, somos conscientes de que tenemos que acercarnos al romancero canario situándolo en el marco de la tradición hispánica, estableciendo relaciones entre las diferentes versiones de un mismo romance. Y sí, es cierto que Espinosa se preocupa por el romancero por lo que ve de insular en él, pero no por ello su labor es menos importante, pues consideramos que precisamente ahí reside su valor universal. Espinosa realiza su recopilación de romances en un momento clave para la consolidación de la literatura canaria, en un momento en el que los autores se preocupan por defender la existencia de una tradición literaria propia, motivo que explica a la perfección por qué Espinosa se interesa por la recolección de romances.

Y precisamente ese valor regional y, al mismo tiempo, universal, que Espinosa otorga al romancero, aunque tal vez lo haga prácticamente sin tener conciencia de ello, es un valor que podemos extrapolar también a la figura del propio Espinosa, bajo cuyo signo continuamos aún hoy, porque nadie es capaz de condensar tan bien en su figura lo insular y lo universal, haciendo que nuestras Islas se proyecten en un espacio mucho más amplio y generando también un diálogo que logra que del verso más pequeño se construya el romance más extenso. Queda pendiente, por tanto,

22 Como muy bien ha señalado Maximiano Trapero, «una correcta interpretación de un romance tradicional no puede contenerse con el estudio particular de un texto aislado, debe ponerlo en comparación y contraste con las otras versiones que de ese mismo romance la tradición ha desperdigado por mil sitios, entendiendo que cada texto es, efectivamente, producto singular de un lugar, pero a la vez fruto variante de un árbol de innumerables ramas» (1987-1988: 441). 
una investigación que profundice en los ecos que este pionero estudio del romancero tuvo en la producción literaria de Agustín Espinosa.

ReCIBIDO: septiembre de 2020; ACEPTADO: noviembre de 2020 


\section{BIBLIOGRAFÍA}

Armas Ayala, Alfonso (1960): Espinosa, cazador de mitos, Puerto de la Cruz: Instituto de Estudios Hispánicos.

Becerra Bolaños, Antonio (2000): «Apuntes para una teoría de la tradición de la vanguardia canaria», en Antonio Becerra Bolaños y Domingo Fernández Agis (coords.), La cultura vanguardista en Canarias: Reflexiones sobre la obra de Agustín Espinosa, Granada: Proyecto Sur Ediciones, 89-105.

Canavaggio, Jean (1994): Historia de la literatura española. Tomo II: el siglo XVI, edición española a cargo de Rosa Navarro Durán), Barcelona: Ariel.

Catalán, Diego (ed.) (1969a): La flor de la marañuela. Romancero General de las Islas Canarias, I, Madrid: Seminario Menéndez Pidal.

Catalán, Diego (ed.) (1969b): La flor de la marañuela. Romancero General de las Islas Canarias, II, Madrid: Seminario Menéndez Pidal.

Espinosa, Agustín (1980): Agustín Espinosa: textos (1927-1936), edición de Alfonso Armas Ayala y Miguel Pérez Corrales, Santa Cruz de Tenerife: Aula de Cultura.

Espinosa, Agustín (1988): Lancelot, 28o $7^{\circ}$ [Guía integral de una isla atlántica], edición de Nilo Palenzuela, Santa Cruz de Tenerife: Editorial Interinsular Canaria.

Gaviño de Franchy, Carlos (ed.) (2009): Agustín Espinosa: a los setenta años de su muerte. 19392009, Canarias: Gobierno de Canarias.

Menéndez Pidal, Ramón (1904): «El romancero español y las Canarias», en Diego Catalán (ed.) (1969), La flor de la marañuela. Romancero General de las Islas Canarias, I, Madrid: Seminario Menéndez Pidal, 15-18.

Padorno, Eugenio (2000): «Una reflexión sobre el signo cultural canario: Viera y Espinosa», en Antonio Becerra Bolaños y Domingo Fernández Agis (coords.), La cultura vanguardista en Canarias: Reflexiones sobre la obra de Agustín Espinosa, Granada: Proyecto Sur Ediciones, 13-25.

Palenzuela, Nilo (2006): "Agustín Espinosa y el mito. Un ejercicio hermenéutico», en Encrucijadas de un insulario, Tenerife: Idea, 117-155.

Pérez Corrales, Miguel (1986a): Agustín Espinosa, entre el mito y el sueño, tomo I, Las Palmas: Cabildo Insular de Gran Canaria.

Pérez Corrales, Miguel (1986b): Agustín Espinosa, entre el mito y el sueño, tomo II, Las Palmas: Cabildo Insular de Gran Canaria.

Pérez Corrales, Miguel (1982-1984): «La conciencia de lo canario en Agustín Espinosa», Estudios Canarios. Anuario del Instituto de Estudios Canarios n. ${ }^{\circ} 28-29,102-105$.

Pérez Minik, Domingo (2018): Facción española surrealista de Tenerife, edición crítica de Roberto García de Mesa, Tenerife: Idea.

Rodríguez Espinosa, Margarita (2009): "Cosas de tócame Roque», en Carlos Gaviño de Franchy (ed.), Agustin Espinosa: a los setenta años de su muerte. 1939-2009, Canarias: Gobierno de Canarias, 71-73.

Trapero, Maximiano (1987-1988): «Agustín Espinosa, primer investigador del romancero canario», Revista de Filología de la Universidad de La Laguna 6-7: 431-456. 